\title{
Control de esfínteres
}

\section{Sphincter control}

Rosalía Garza-Elizondo

Durante el desarrollo psicomotor del niño, el control voluntario de esfínteres es parte fundamental de su crecimiento, por su relevancia social, porque su retraso o regresión puede ocasionar problemas clínicos en el área personal, familiar y social.

En el niño pequeño, las micciones son involuntarias, con vaciados vesicales incompletos. Durante el primer año de vida, la vejiga se vacía mediante el arco reflejo parasimpático medular, sin intervenir en el control cortical.

En la mayoría de los niños, el control voluntario de la micción se va desarrollando entre los 18 meses y los 3 años. La continencia se alcanza cuando el niño es capaz de lograr la contracción voluntaria del esfínter externo de la uretra, mientras que el detrusor, que no está sometido a ninguna supresión cortical, se contrae de forma involuntaria. ${ }^{1}$

En la mayoría de los casos, la secuencia en la adquisición del control voluntario de los esfínteres se inicia con el control intestinal durante el sueño, seguido del control fecal en las horas de vigilia, posteriormente el control diurno de la orina y al final el nocturno. Muchos niños adquieren el control intestinal y vesical de manera simultánea. ${ }^{2}$ Existen variaciones interindividuales e interculturales, donde influyen factores educacionales, familiares, sociales, psicológicos y hereditarios.

La continencia urinaria nocturna es la más difícil de conseguir, solo se logra en $26 \%$ de los niños a los 18 meses de vida. A los 3 años, $75 \%$ de los varones y $80 \%$ de las niñas permanecen secos durante la noche. Pero si a los 5 años no tiene aún un control urinario nocturno se diagnostica enuresis, que sucede en 15-20\% de la población en general.

En cuanto a la continencia fecal no debe sobrepasar los 4 años, si ésta se prolonga se diagnostica encopresis y puede originar graves problemas sociales, familiares y psicológicos. En la mayoría de los casos secundaria a estreñimiento.
Médico adscrita al departamento de Consulta Externa. Instituto Nacional de Pediatría, Ciudad de México.

Recibido: 8 de julio 2019

Aceptado: 5 de diciembre 2019

\section{Correspondencia} Rosalía Garza-Elizondo rgarzaeli@gmail.com

Este artículo debe citarse como Garza-Elizondo R. Control de esfínteres. Acta Pediatr Mex. 2020;41(1):40-2. 
Para alcanzar el control de esfínteres se requiere la adecuada adquisición de los hitos del desarroIlo: que el niño camine, comprenda y se exprese verbalmente; que tenga un buen nivel de maduración afectiva, con desarrollo de tendencias anales y uretrales, y que cuente con una familia preparada y dispuesta a acompañar y guiar el proceso de entrenamiento.

Para el inicio del entrenamiento para el control de esfínteres se distinguen tres etapas:

1. El niño es capaz de percibir que ha orinado o evacuado y es capaz de trasmitirlo a sus padres.

2. Percibe la sensación de evacuar y la trasmite en los momentos previos o durante el acto, pero es incapaz de retenerla.

3. Puede retener o decidir la expulsión de heces y orina.

Además, existen signos que indican que el niño se encuentra preparado para este entrenamiento:

- Permanecer secos durante varias horas.

- Mostrar interés por sentarse en la bacinica o en la tasa del baño, expresando signos visibles de prepararse para orinar o evacuar.

- Demandar cambio de pañal posterior a la evacuación.

- Comprender y ejecutar órdenes verbales simples.

Uno de los métodos más usados para el control de esfínteres es el del horario: el niño comienza a usar la bacinica o retrete y a sentarse en ella completamente vestido, utilizando ropa cómoda; después practica bajarse la ropa interior, durante $\leq 5$ o 10 minutos y vuelve a vestirse. Se le explica varias veces y ya establecido este entrenamiento, la madre trata de anticipar la necesidad de evacuación del niño y reforzarla de forma positiva para conseguir una evacuación exitosa. También se alienta al niño a que practique usar el sanitario siempre que sienta la necesidad de evacuar, si se usa inodoro normal, deberá usar adaptador de asiento y un taburete. ${ }^{3}$ Se le debe enseñar a accionar el depósito de agua y a lavarse las manos después de cada evacuación. Para los niños que no tienen horarios predecibles, este plan es difícil y debe diferirse el entrenamiento hasta que puedan anticipar la evacuación por sí mismos.

El proceso de aprendizaje es de entre 3 a 12 meses hasta que el niño adquiera independencia para ir solo al baño durante el día.

Durante el proceso de entrenamiento, $20 \%$ de los niños desarrolla rechazo al uso del sanitario. Este comportamiento se asocia con consecuencias negativas: retención de heces y orina, riesgo de trastornos de eliminación: enuresis y encopresis, y otras dificultades psicológicas y fisiológicas derivadas, que en caso de producirse, deberán ser atendidas adecuadamente por el pediatra. ${ }^{4}$

Si un niño expresa su negativa a ir al baño, debe volver a intentarlo después de comer, pero si continúa, la mejor estrategia es posponer durante por lo menos varias semanas o hasta tres meses. Esto permite la confianza y la cooperación para ser restablecida entre los padres y el niño. Después de este receso, la mayoría de los niños están listos. Si los intentos repetidos no tienen éxito, o si el niño es mayor de cuatro años, deberá consultarse con el pediatra para explorar aspectos de la relación padre-hijo o para descartar anomalías del desarrollo neurológico..$^{5-8}$

La negativa a usar el retrete también puede representar manipulación. En estas situaciones se aconseja a los padres que no presionen a los niños, que ofrezcan incentivos $y$, si es posible, que presten más atención y cuidados al niño en momentos que no impliquen controlar los esfínteres. 
Las actividades en grupo que se desarrollan en guarderías participan en el alcance del control, cuando son llevadas a cabo en un ambiente cordial, sin castigos, sin obligar o ridiculizar a los niños que no contribuyen a alcanzar la meta deseada.

Deben evitarse las luchas de poder, porque suelen provocar regresión de cualquier progreso que se haya realizado, dañar la relación padre-hijo y la autoimagen del niño. ${ }^{5,6,9}$ Los niños que controlan esfínteres pueden dejar de hacerlo cuando tienen trastornos físicos o emocionales, o cuando sienten la necesidad de recibir mayor atención o cuando nace un hermano, al observar los cuidados del nuevo miembro de la familia y el cambio de pañal, los niños experimentan regresiones y requieren volver a utilizar el pañal.

Las causas orgánicas del fracaso no son comunes. La explicación más probable para el "fracaso" es que el niño no está listo y los intentos de entrenarlo serán inútiles. Los hábitos intestinales también juegan un papel muy importante porque si existe estreñimiento, por lo general tendrá dolor al evacuar, y siempre que pueda tratará de evitarlo, lo que hará difícil el proceso de control, incluso traerá como consecuencia la retención voluntaria de materia fecal creando otro tipo de problemas intestinales. Los niños con diarrea intermitente pueden experimentar aparentes retrocesos cuando ya controlaban y de repente se vuelven incontinentes ante la urgencia de evacuar.

En conclusión, el entrenamiento en el uso del sanitario no debe iniciarse antes de los 18 meses. A partir de esa edad existe mucha variabilidad a la hora de determinar el momento adecuado en el que el niño se encuentra preparado para el inicio del aprendizaje. La decisión de los padres de iniciar el entrenamiento debe basarse en la madurez socioemocional y psicológica del niño. Diversos estudios muestran que cuanto más temprano sea el entrenamiento intensivo en el uso del inodoro, a menor edad adquirirán este aprendizaje, pero también tardarán más tiempo en completar el entrenamiento. ${ }^{10,11}$

En el caso de los niños que NO logran comenzar el control de esfínteres, lo conducente es esperar un tiempo prudente con un entrenamiento supervisado, reevaluando los datos del niño y medio familiar. Las dificultades en el control adecuado pueden ser un síntoma dentro de uno complejo, donde el trabajo pediátrico deberá profundizar y valorar adecuadamente la coexistencia de enfermedades subyacentes.

\section{REFERENCIAS}

1. Aleo LE, De Miguel LB, Pérez RO. Desarrollo de la continencia urinaria en el niño. Clínicas Urológicas de la Complutense, Servicio de Publicaciones. UCM, Madrid 2000; 8:663-669.

2. Blum NJ. Taubman B, Osborne ML. Behavioral characteristic of children with stool toileting refusal. Pediatrics. 1997; 99: 50-53.

3. Baxter C, Gorodzinsky F. Toilet learning: Anticipatory guidance with a child-oriented approach. Canadian Paediatric Society Statement. Paediatr Child Health. 2000; 5 (6): 33335. https://doi.org/10.1093/pch/5.6.333

4. Bezos SL, Escribano CE. ¿Qué esconden los problemas de control de esfínteres? A propósito de un caso. Rev Pedriatr Aten Primaria. 2012; 14: 317-21.

5. Luxem M. Behavioral toilet training in early childhood: Research, practice and implications. J Dev Behav Pediatr. 1994; 15: 370-8.

6. Luxem MC, et al. Behavioral-medical treatment of pediatric toileting refusal. J Dev Behav Pediatr. 1997; 18: 34-41.

7. Howe AC, Walker CE. Behavioral management of toilet training, enuresis and encopresis. Pediatr Clin North Am. 1992; 39: 413-32. https://doi.org/10.1016/\$00313955(16)38336-5.

8. Taubman B. Toilet training and toileting refusal for stool only: A prospective study. Pediatrics. 1997; 99: 54-8. https://doi. org/10.1542/peds.99.1.54.

9. Schmitt BD. Toilet training refusal: Avoid the battle and win the war. Contemp Ped. 1987:32-50.

10. Sadock BJ, Sadock VA. Trastornos de la eliminación. En: Sadock BJ, Sadock VA, Kaplan \& Sadock. Sinopsis de Psiquiatría. Ciencias de la Conducta/Psiquiatría Clínica. 10a ed. Barcelona: Wolters Kluwer-Lippincott Williams \& Wilkins, 2009:1245-49.

11. Taubman B, Blum NJ, Nemeth N. Stool toileting refusal; a prospective intervention targeting parental behavior. Arch Pediatr Adolesc Med. 2003;157:1193-1196. doi:10.1001/ archpedi.157.12.1193 